\title{
Clinical Characteristics and Psychotropic Drug Prescription Patterns of Bipolar Disorder Patients with a History of Suicidal Attempts: Findings from the REAP-BD, Korea
}

\author{
Seon-Cheol Park ${ }^{1}$, Kiwon Kim², Ok-Jin Jang ${ }^{3}$, Seung-Gon Kim ${ }^{4}$, Jung Goo Lee ${ }^{1}$, Joon Hyuk Park ${ }^{5}$, \\ Joonho Choi ${ }^{6}$, Dong-Woo Lee ${ }^{7}$, Shih-Ku Lin ${ }^{8}$, Chay Hoon Tan ${ }^{9}$, Naotaka Shinfuku ${ }^{10}$, and Yong Chon Park ${ }^{6}$ \\ ${ }^{1}$ Department of Psychiatry, Inje University Haeundae Paik Hospital, Busan, Republic of Korea \\ ${ }^{2}$ Department of Psychiatry, Veteran Health Service Medical Center, Seoul, Republic of Korea \\ ${ }^{3}$ Department of Psychiatry, Bugok National Hospital, Changyeong, Republic of Korea \\ ${ }^{4}$ Department of Psychiatry, Chosun University Hosptial, Gwangju, Republic of Korea \\ ${ }^{5}$ Department of Psychiatry, Jeju National University, Jeju, Republic of Korea \\ ${ }^{6}$ Department of Neuropsychiatry, Hanyang University Guri Hospital, Guri, Republic of Korea \\ ${ }^{7}$ Department of Psychiatry, Inje University Sanggye Paik Hospital, Seoul, Republic of Korea \\ ${ }^{8}$ Psychiatric Center, Taipei City Hospital, Taipei, Taiwan \\ 9Department of Pharmacology, National University Hospital, Singapore, Singapore \\ ${ }^{10}$ Department of Social Welfare, School of Human Sciences, Seinan Gakuin University, Fukuoka, Japan
}

Our study aimed to analyze the clinical characteristics and psychotropic prescription patterns of a history of suicide attempts in South Koreans with bipolar disorder (BD), by using only Korean data from the Research on Asian Psychotropic Prescription Pattern for Bipolar disorder. The patterns of clinical characteristics and psychotropic drug use were compared among 53 patients with a history of suicide attempts and 297 without this history; the potential effects of confounding variables were adjusted with binary logistic analyses for discrete variables and analyses of covariance for continuous variables. After adjusting the effects of age, sex, duration of illness, and enrollment as an outpatient, patients with a history of suicide attempts were characterized by a significantly more prevalent depressive episode, lower prevalent remission state, lower levels of hemoglobin, and more use of antidepressants, anxiolytics, and hypnotics compared to those without lifetime suicide attempt. The inability to plan goal-directed behavior may be an intervening factor in the relationship between suicide attempts and depression in BD. Relatively low hemoglobin levels can be associated with manic episodes in patients with a history of suicide attempts and the use of antidepressants, anxiolytics, or hypnotics can be associated with suicide attempts in BD patients.

Psychiatry Investig 2019;16(6):459-463

Key Words Antidepressant, Bipolar disorder, Depressive episode, Hemoglobin, Suicide attempt.

\section{INTRODUCTION}

Bipolar disorder (BD) has been considered a major risk factor for suicide. ${ }^{1,2} \mathrm{~A}$ systemic review has identified previous suicide attempts as a major factor for completed suicide in $\mathrm{BD}$ patients along with early onset, family history of suicide among

Received: November 26, 2018 Revised: January 18, 2019 Accepted: March 10, 2019

$\bowtie$ Correspondence: Seon-Cheol Park, MD, PhD

Department of Psychiatry, Inje University Haeundae Paik Hospital, 875 Haeundaero, Haeundae-gu, Busan 48108, Republic of Korea

Tel: +82-51-797-3300, Fax: +82-51-797-0298

E-mail: cogito-ergo-sum@hanmail.net

(c) This is an Open Access article distributed under the terms of the Creative Commons Attribution Non-Commercial License (https://creativecommons.org/licenses/by$\mathrm{nc} / 4.0$ ) which permits unrestricted non-commercial use, distribution, and reproduction in any medium, provided the original work is properly cited. first-degree relatives, and other factors. ${ }^{3}$ Among 362 patients diagnosed with BD, based on the Diagnostic and Statistical Manual of Mental Disorders, fourth edition, text revision, ${ }^{4} \mathrm{pa}-$ tients with prior suicide attempt were characterized by polarity at onset, increased number of psychiatric hospitalization, psychiatric comorbidity, and treatment with lithium and polypharmacy ( 4 or more psychotropic drugs) compared to those without prior suicide attempts. ${ }^{5}$ Moreover, the actigraphic findings revealed that the sleep and circadian rhythms of morning preference, vigorous circadian type, and earlier start of daily activity were potential trait differences in $\mathrm{BD}$ patients with suicide attempts from those without such attempts. ${ }^{6}$ Similar to the studies based on other ethnicities, this study aimed to investigate clinical correlations of suicide attempts in Asian patients 
with BD, particularly in Koreans. The Research on Asian Psychotropic Prescription Pattern for Bipolar Disorder (REAP$\mathrm{BD})$ study is the largest ongoing international survey of psychotropic prescriptions for patients with $\mathrm{BD}$ in Asia. By using the Korean data from the REAP-BD study, we aimed to identify the lifetime suicide attempt-related patterns of clinical characteristics and psychotropic drug use in Koreans.

\section{METHODS}

During the REAP-BD study period from September to December 2018, BD patients will be enrolled as study participants from 16 Asian countries or areas, including Bangladesh, China, Hong Kong, India, Indonesia, Japan, Korea, Malaysia, Myanmar, Pakistan, Philippines, Singapore, Sri Lanka, Taiwan, Thailand, and Vietnam. The research protocols and informed consent forms were approved by the institutional review boards of all survey centers under the direction of Taipei City Hospital, Taipei, Taiwan (receipt number: TCHIRB10605117-E). The only inclusion criterion was a diagnosis of BD (F31) made using the International Classification of Diseases, tenth revision. ${ }^{7}$ To reflect accurate clinical situations of Asian regions, the specific exclusion criteria were not defined. Moreover, 350 South Korean BD patients were enrolled in the study from 4 university-affiliated general hospitals, 2 psychiatric hospitals, and 1 veterans health service medical center. The recruited number of Korean subjects with BD in each of the 7 centers ranged from 30 to 100 . Clinical psychiatrists of the survey centers collected information on demographic and clinical characteristics, which included the number of suicide attempts, rapid cycling, long-term course, compete blood cell count and blood chemistry findings, psychotropic prescription patterns. Before the survey, conferences were held to promote the consistency of data collection and entry. The data collection center was located at the Taipei City Psychiatric Center, Taipei, Taiwan.

We developed definitions of certain terms and used classifications as standards for the study. Suicide attempts were dichotomously evaluated as either its presence or absence in the REAP-BD study, although suicide attempts were subgrouped into the impulsive and planed patterns by a cluster analysis of 888 Korean suicide attempts. ${ }^{8}$ Rapid cycling was defined as the presence of four or more episodes of $\mathrm{BD}$ within 1 year, based on the concept of Dunner and Fieve. 9 Seasonality was considered as patterns with peaks for manic episodes in spring-summer, peaks for depressive episodes in early winter, and peaks for mixed episodes in early spring and summer. ${ }^{10}$ Body mass index (BMI) was calculated as weight $(\mathrm{kg}) /$ height $(\mathrm{m})^{2}$. The use of psychotropic drugs were grouped according to the Anatomical and Therapeutic Chemical (ATC) Classification in- dex of the World Health Organization Collaborating Center for Drug Statistics Methodology. ${ }^{11}$ Because of the partly outdated groupings of the ATC Classification index, lithium and clonazepam were respectively grouped as a mood stabilizer and an anxiolytic.

We used $\chi^{2}$ tests for discrete variables and independent $t-$ tests for continuous variables for our statistical analyses, and the patterns of clinical characteristics and psychotropic drug use were compared between $\mathrm{BD}$ patients with and without a history of suicide attempts. In addition, the potential effects of confounding factors were adjusted by using binary logistic analyses for discrete variables and analyses of covariance for continuous variables. Statistical significance was set at $\mathrm{p}<0.05$ (two-tailed) for all tests. All statistical analyses were conducted using IBM SPSS 24 (IBM Co., Armonk, NY, USA).

\section{RESULTS}

After statistical analyses of 350 participants, $15.1 \%(n=53)$ of the subjects reported a history of suicide attempts. Moreover, $5.1 \%(\mathrm{n}=18)$ and $2.9 \%(\mathrm{n}=10)$ of patients reported attempting suicide within the past year and the past month, respectively. In terms of baseline characteristics, the proportion of outpatients was significantly smaller for BD patients with a history of suicide attempts rather than for those without such attempts $\left(\chi^{2}=4.217, p=0.040\right)$. However, there were no statistically significant differences in age, sex, and employment. Age, sex, duration of illness, and enrollment as an outpatient were defined as the confounding factors, which could influence the clinical characteristics and psychotropic drug prescription patterns in lifetime suicide attempt subjects.

As shown in Table 1, adjusting the potential effects of confounding factors, participants with a history of suicide attempts presented a significantly more prevalent depressive episode [adjusted odds ratio $(\mathrm{aOR})=1.925, \mathrm{p}=0.040$ ], less prevalent remission state $(\mathrm{aOR}=0.519, \mathrm{p}=0.040)$, and lower levels of hemoglobin $(\mathrm{F}=5.924, \mathrm{p}=0.016)$ than those without such attempts when the potential effects of the enrollment as an outpatient were adjusted. Furthermore, those with a history of suicide attempts used significantly more antidepressants (aOR=2.776, $\mathrm{p}=0.005)$, anxiolytics $(\mathrm{aOR}=1.920, \mathrm{p}=0.045)$, and hypnotics $(\mathrm{aOR}=2.946, \mathrm{p}=0.018)$ than those without. In contrast, there were no significant differences in the duration of $\mathrm{BD}$, duration of untreated illness, current manic and mixed episode, duration of current episode, polarity at onset, rapid cycling in lifetime, seasonality in the past year, seasonality in lifetime, levels of BMI, white blood cell count, platelet count, total cholesterol and triglyceride, and uses of mood stabilizer, antipsychotic and anti-parkinsonian drugs between the two groups. 
SC Park et al.

Table 1. Clinical characteristics and psychotropic prescription patterns of bipolar disorder patients with and without a history of suicide attempts

\begin{tabular}{|c|c|c|c|c|c|c|}
\hline & \multirow{2}{*}{$\begin{array}{l}\text { Total sample } \\
(\mathrm{N}=350)\end{array}$} & \multicolumn{2}{|c|}{ Lifetime suicidal attempt } & \multirow{2}{*}{$\begin{array}{c}\text { Statistical } \\
\text { coefficients }\end{array}$} & \multirow{2}{*}{$\begin{array}{c}\text { Unadjusted } \\
\text { p-value }\end{array}$} & \multirow{2}{*}{$\begin{array}{l}\text { Adjusted } \\
\text { p-value* }\end{array}$} \\
\hline & & Present $(\mathrm{N}=53)$ & Absent $(\mathrm{N}=297)$ & & & \\
\hline Age, mean (SD) years & $43.6(15.2)$ & $45.0(16.2)$ & $43.4(15.0)$ & $\mathrm{t}=0.720$ & 0.472 & - \\
\hline Female, N (\%) & $210(60.0)$ & $32(60.4)$ & $178(59.9)$ & $\chi^{2}=0.004$ & 0.951 & - \\
\hline Employed, N (\%) & $63(18.0)$ & $8(15.1)$ & $55(18.5)$ & $\chi^{2}=0.357$ & 0.550 & 0.965 \\
\hline Outpatient, N (\%) & $197(56.3)$ & $23(43.4)$ & $174(58.6)$ & $\chi^{2}=4.217$ & 0.040 & - \\
\hline Duration of illness, $\mathrm{N}(\%)^{\dagger}$ & & & & $\chi^{2}=1.946$ & 0.857 & - \\
\hline$<6$ months & $22(6.7)$ & $2(4.0)$ & $20(7.2)$ & & & \\
\hline 6-12 months & $6(1.8)$ & $1(2.0)$ & $5(1.8)$ & & & \\
\hline $1-5$ years & $50(15.2)$ & $9(18.0)$ & $41(14.7)$ & & & \\
\hline $5-10$ years & $75(22.9)$ & $14(28.0)$ & $61(21.9)$ & & & \\
\hline $10-20$ years & $87(26.5)$ & $12(24.0)$ & $75(27.0)$ & & & \\
\hline$>20$ years & $88(26.8)$ & $12(24.0)$ & $76(23.2)$ & & & \\
\hline Duration of untreated illness, $\mathrm{N}(\%)^{\ddagger}$ & & & & $\chi^{2}=0.520$ & 0.914 & - \\
\hline$<6$ months & $115(42.1)$ & $17(43.6)$ & $98(41.9)$ & & & 0.808 \\
\hline 6-12 months & $53(19.4)$ & $6(15.4)$ & $47(20.1)$ & & & 0.418 \\
\hline $1-5$ years & $70(25.6)$ & $11(28.2)$ & $59(25.2)$ & & & 0.464 \\
\hline$>5$ years & $35(12.8)$ & $5(1.8)$ & $30(12.8)$ & & & 0.531 \\
\hline Polarity at onset, $\mathrm{N}(\%)^{\S}$ & & & & $\chi^{2}=0.794$ & 0.373 & 0.502 \\
\hline Depressive episode & $79(32.0)$ & $16(38.1)$ & $63(31.0)$ & & & \\
\hline Manic episode & $166(67.8)$ & $26(61.9)$ & $140(69.0)$ & & & \\
\hline \multicolumn{7}{|l|}{ Current episode, N (\%) } \\
\hline Depressive episode & $36(10.3)$ & $13(24.5)$ & $23(7.7)$ & $\chi^{2}=13.730$ & $<0.0001$ & 0.040 \\
\hline Manic episode & $54(15.4)$ & $6(11.3)$ & $48(16.2)$ & $\chi^{2}=0.808$ & 0.369 & 0.313 \\
\hline Mixed episode & $16(4.6$ & $4(7.5)$ & $12(4.0)$ & $\chi^{2}=1.268$ & 0.260 & 0.241 \\
\hline Remission & $216(61.7)$ & $27(50.9)$ & $189(63.6)$ & $\chi^{2}=3.067$ & 0.080 & 0.040 \\
\hline Duration of current episode, $\mathrm{N}(\%)^{\|}$ & & & & $\chi^{2}=4.484$ & 0.345 & - \\
\hline$<1$ month & $77(24.2)$ & $10(21.3)$ & $67(24.7)$ & & & 0.122 \\
\hline 1-3 months & $106(33.3)$ & $11(23.4)$ & $95(35.1)$ & & & 0.973 \\
\hline $3-6$ months & $41(12.9)$ & $9(19.1)$ & $32(11.8)$ & & & 0.078 \\
\hline 6-12 months & $19(6.0)$ & $4(8.5)$ & $15(5.5)$ & & & 0.085 \\
\hline$>1$ year & $75(23.6)$ & $13(27.7)$ & $62(22.9)$ & & & 0.099 \\
\hline Rapid cycling in lifetime, N (\%) & $11(3.1)$ & $3(5.7)$ & $8(2.7)$ & $\chi^{2}=1.300$ & 0.254 & 0.271 \\
\hline Seasonality in lifetime, N (\%) & $14(4.0)$ & $4(7.5)$ & $10(3.4)$ & $\chi^{2}=2.047$ & 0.153 & 0.618 \\
\hline Body mass index, mean $(\mathrm{SD}) \mathrm{kg} / \mathrm{m}^{2}$ & $24.3(4.1)$ & $23.8(4.6)$ & $24.4(4.0)$ & $\mathrm{t}=-1.016$ & 0.310 & 0.275 \\
\hline \multicolumn{7}{|l|}{$\mathrm{CBC}$ and blood chemistries } \\
\hline White blood cell, mean $(\mathrm{SD}) \times 10^{3} / \mathrm{uL}$ & $6.6(2.2)$ & $6.5(2.1)$ & $6.7(2.3)$ & $\mathrm{t}=-0.412$ & 0.681 & 0.839 \\
\hline Hemoglobin, mean (SD) g/d & $13.2(1.7)$ & $12.5(1.8)$ & $13.7(1.6)$ & $t=-2.772$ & 0.006 & 0.016 \\
\hline Platelet, mean $(\mathrm{SD}) \times 10^{3} / \mathrm{u}$ & $241.0(59.3)$ & $243.0(63.4)$ & $240.6(58.7)$ & $\mathrm{t}=0.210$ & 0.834 & 0.954 \\
\hline Total cholesterol, mean (SD) mg/dL & $181.2(38.4)$ & $174.3(38.1)$ & $182.9(38.5)$ & $\mathrm{t}=-1.137$ & 0.257 & 0.248 \\
\hline Triglyceride, mean (SD) mg/dL & $137.0(105.6)$ & $111.3(52.3)$ & $142.2(112.8)$ & $\mathrm{t}=-1.224$ & 0.223 & 0.601 \\
\hline Mood stabilizer, N (\%) & $327(93.4)$ & $47(88.7)$ & $280(94.3)$ & $\chi^{2}=2.295$ & 0.130 & 0.092 \\
\hline Antipsychotic, N (\%) & $317(90.6)$ & $47(88.7)$ & $270(90.9)$ & $\chi^{2}=0.262$ & 0.609 & 0.641 \\
\hline Antidepressant, N (\%) & $64(18.3)$ & $17(32.1)$ & $47(15.8)$ & $\chi^{2}=7.949$ & 0.005 & 0.005 \\
\hline Anxiolytic, N (\%) & $167(47.7)$ & $32(60.4)$ & $135(45.5)$ & $\chi^{2}=4.015$ & 0.045 & 0.045 \\
\hline Hypnotic, N (\%) & $30(8.6)$ & $10(18.9)$ & $20(6.7)$ & $\chi^{2}=8.450$ & 0.004 & 0.018 \\
\hline Anti-parkinson drug, n (\%) & $45(12.9)$ & $9(17.0)$ & $36(12.1)$ & $\chi^{2}=0.948$ & 0.330 & 0.205 \\
\hline
\end{tabular}

*adjusted for potential effects of age, sex, enrollment as an outpatient and duration of illness, ${ }^{\dagger} \mathrm{N}=328,{ }^{\ddagger} \mathrm{N}=273,{ }^{\S} \mathrm{N}=245$, "N=318. CBC: complete blood cell count, SD: standard deviation 


\section{DISCUSSION}

In summary, our findings indicate that $\mathrm{BD}$ patients with a history of suicide attempts have a more prevalent depressive episode, less prevalent remission state, lower levels of hemoglobin, and more prescriptions for antidepressants, anxiolytics, and hypnotics compared to those without such attempts. A previous study has presented that suicidality is more prevalent in subjects with bipolar depression than in subjects with depressive mania and pure mania. ${ }^{12}$ Also, subjects with bipolar depression who have with a history of suicide attempts have been noted to have reduced gray matter volumes in the dorsolateral prefrontal cortex, orbitofrontal cortex, anterior cingulate cortex, and superior temporal cortex, along with in other brain areas. Hence, an inability to plan goal-directed behavior has been proposed as an intervening variable between suicidality and bipolar depression. ${ }^{13}$ Furthermore, circadian behavior in BD can be influenced by the CLOCK rs1801260 gene polymorphism: a study has shown that increased suicidality and depressive cognitive distortion is present in CLOCK rs $1801260^{*} \mathrm{C}$ carrier patients with bipolar depression. ${ }^{14}$ Partly consistent with our findings, the relationship between previous suicide attempts and bipolar depression has been evidenced using several neurobiological correlates. The prevalence of anemia may differentiate chronic patients with BD or other psychiatric disorders from the general population, and it may also differentiate patients with schizophrenia from those with affective disorders; remarkably, an inverse relationship between hemoglobin level and a history of suicide attempts may be suggested by these findings. ${ }^{15,16}$ Such a relationship between hemoglobin levels and suicide attempts cannot be explained simply. By the findings of Wysokinski and Szczepocka, ${ }^{16}$ subnormal erythrocyte counts were more prevalent in patients with $\mathrm{BD}$ than in those with schizophrenia or unipolar depression. Since BD is linked to an imbalance of fluid homeostasis, we speculate that lower levels of hemoglobin in $\mathrm{BD}$ patients with a history of suicide attempts can be associated with the concentration changes in blood components that accompany manic episodes in BD. Moreover, it may be assumed that manic features could have intervening effects on an inverse relationship between hemoglobin levels and suicide attempts in BD patients. Furthermore, an increased risk of suicide attempts is positively correlated with the use of antidepressant, benzodiazepine, or valproic acid, according to a 3.5-year follow-up study for 826 inpatient with BD in Finland. ${ }^{17}$ On the contrary, it might be assumed that antidepressants, anxiolytics, or hypnotics could be used to treat bipolar depression. ${ }^{18}$ Regardless of the causality relationship between antidepressants, anxiolytics, or hypnotics and suicide attempts, the findings supported the notion that the use of antidepressants is controversial in the treat- ment of $\mathrm{BD}$, including bipolar depression. ${ }^{19}$

Our study has several limitations. First, because the REAPBD study was not considered an epidemiological survey, generalization and extrapolation of our findings should be limited. Second, psychiatric comorbidity was not evaluated, and thus, its potential effects on the findings could not be adjusted. Third, although there was a consensus meeting before the initiation of our study, inter-rater reliability for evaluating clinical characteristics were not considered. Fourth, statistical significances may potentially not correspond to clinical ones. Despite these limitations, our findings are valuable in indicating the presence of lower levels of hemoglobin, more prevalent depressive episode, less prevalent remission state, and more use of antidepressants, anxiolytics, or hypnotics in Koreans with a history of suicide attempts than in those without such attempts. Our results also offer another reference in further interpretation or comparison for the overall data of Asians with $\mathrm{BD}$ in the REAP-BD study.

\section{Acknowledgments}

This work was supported by the 2018 Inje University Research Grant.

\section{Conflicts of Interest}

The authors have no potential conflicts of interest to disclose.

\section{Author Contributions}

Conceptualization: Park S-C, Lin S-K, Tan CH, Shinfuku N, Park YC. Data curation: Park S-C, Kim K, Kim S-G, Lee JG, Park JH, Choi J, Park YC. Funding acquisition: Park S-C. Investigation: Park S-C, Kim K, Kim S-G, Lee JG, Park JH, Choi J, Lee D-W, Park YC. Methodology: Park S-C, Lin S-K, Tan CH, Shinfuku N, Park YC. Project administration: Park S-C, Lin S-K, Tan CH, Shinfuku N, Park YC. Supervision: Lin S-K, Tan CH, Shinfuku N, Park YC. Writing—original draft: Park S-C. Writing—review \& editing: Park S-C, Lee D-W, Park YC.

\section{ORCID iDs}

$\begin{array}{ll}\text { Seon-Cheol Park } & \text { https://orcid.org/0000-0003-3691-4624 } \\ \text { Kiwon Kim } & \text { https://orcid.org/0000-0001-7594-0142 } \\ \text { Ok-Jin Jang } & \text { https://orcid.org/0000-0002-6272-7825 } \\ \text { Seung-Gon Kim } & \text { https://orcid.org/0000-0002-5000-7222 } \\ \text { Jung Goo Lee } & \text { https://orcid.org/0000-0003-3393-2667 } \\ \text { Jung Goo Lee } & \text { https://orcid.org/0000-0003-3393-2667 } \\ \text { Joon Hyuk Park } & \text { https://orcid.org/0000-0002-0396-5284 } \\ \text { Joonho Choi } & \text { https://orcid.org/0000-0003-0597-0877 } \\ \text { Dong-Woo Lee } & \text { https://orcid.org/0000-0002-6383-1974 } \\ \text { Shih-Ku Lin } & \text { https://orcid.org/0000-0002-5123-0389 } \\ \text { Chay Hoon Tan } & \text { https://orcid.org/0000-0002-6399-0668 } \\ \text { Naotaka Shinfuku } & \text { https://orcid.org/0000-0002-7390-9077 } \\ \text { Yong Chon Park } & \text { https://orcid.org/0000-0002-3019-5748 }\end{array}$

\section{REFERENCES}

1. Pan Z, Gui C, Zhang J, Zhu J, Cui D. Detecting manic state of bipolar disorder based on support vector machine and Gaussian mixture model using spontaneous speech. Psychiatry Investig 2018;15:695-700.

2. Muneer A, Mazommil R. The stage of major mood disorders: clinical and neurobiological correlates. Psychiatry Investig 2018;15:747-758.

3. Plans L, Barrot C, Nieto E, Rios J, Schulze TG, Mitjans M, et al. A. Association between completed suicide and bipolar disorder: A systemic re- 
view of the literature. J Affect Disord 2019;242:111-122.

4. American Psychiatric Association. Diagnostic and Statistical Manual of Mental Disorders, 4th Edition. Washington, DC: American Psychiatric Association; 1994

5. Dell'Osso B, Vismara M, Dobrea C, Cremaschi L, Grancini B, Arici C, et al. Clinical characterization of Italian suicide attempters with bipolar disorder. CNS Spectr 2018;23:271-277.

6. Benard V, Etain B, Vaiva G, Boudebesse C, Yeim S, Benizri C, et al. Sleep and circadian rhythms as possible trait marker of suicidal attempt in bipolar disorders: an actigraphy study. J Affect Disord 2019;244:1-8.

7. World Health Organization. The ICD-10 Classification of Mental and Behavioral Disorders, Clinical Descriptions and Diagnostic Guidelines. Geneva: World Health Organization; 1992.

8. Kim H, Kim B, Kim SH, Park CHK, Kim EY, Ahn YM. Classification of attempted suicide by cluster analysis: A study of 888 suicide attempters presenting to the emergency department. J Affect Disord 2018;235:184190.

9. Dunner D, Fieve R. 1974. Clinical factors in lithium carbonate prophylaxis failure. Arch Gen Psychiatry 1974;30:229-233.

10. Fellinger M, Waldhoer T, Konig D, Hinterbuchinger B, Pruckner N, Baumgartner J, et al. Seasonality in bipolar disorder: effect of sex and age. J Affect Disord 2019;24:322-326.

11. World Health Organization. Anatomical Therapeutic Chemical (ATC) Classification System. Available at: https://www.whocc.no/atc/structure and_principles/. Accessed September 30, 2018.
12. Dilsaver SC, Chen YW, Swann AC, Shoaib AM, Tsai-Dilsaver Y, Krajewski KJ. Suicidality, panic disorder and psychosis in bipolar depression, depressive-mania and pure-mania. Psychiatry Res 1997;73:47-56.

13. Benedetti F, Radaelli D, Poletti S, Locatelli C, Falini A, Colombo C, Smeraldi E. Opposite effects of suicidality and lithium on gray matter volumes in bipolar depression. J Affect Disord 2011;135:139-147.

14. Benedetti F, Riccaboni R, Dallaspezia S, Locatelli C, Smeraldi E, Colombo C. Effects of CLOCK gene variants and early stress on hopelessness and suicide in bipolar depression. Chronobiol Int 2015;32:1156-1161.

15. Korkmaz S, Yildız S, Korucu T, Gundogan B, Sunbul ZE, Korkmaz H, et al. Frequency of anemia in chronic psychiatry patients. Neuropsychiatr Dis Treat 2015;11:2737-2741.

16. Wysokinski A, Szczepocka E. Red blood cells parameters in patients with acute schizophrenia, unipolar depression and bipolar disorder. Psychiatr Danub 2018;30:323-330.

17. Toffol E, Hätönen T, Tanskanen A, Lönnqvist J, Wahlbeck K, Joffe G, et al. Lithium is associated with decrease in all-cause and suicide mortality in high-risk bipolar patients: a nationwide registry-based prospective cohort study. J Affect Disord 2015;183:159-165.

18. Bowden CL, Singh V. The use of antidepressants in bipolar disorder patients with depression. Expert Opin Pharmacother 2016;17:17-25.

19. American Psychiatric Association. Diagnostic and Statistical Manual of Mental Disorders, 5th Ed. Washington, DC: American Psychiatric Association; 2013. 